\section{Laparoscopic reversal of the Hartmann procedure - a video vignette}

doi:10.1111/codi.14859

\section{Dear Editor,}

The Hartmann procedure is a standard life-saving operation for an acute left colonic complication [1]]. In the past it has been performed in cases with complicated inflammation of the left colon, bowel obstruction caused by colon cancers or in the case of insufficiency of anastomoses, or in urgent operations after traumatic bowel injuries, when making an anastomosis carries very high risk [2-4]]. It can generally be considered a temporary procedure with the intention of reversing it later on. The mean time interval between the initial procedure and the reversal is 181.6 days (range 95330 days). The mortality rate is $0.7 \%$ and $16.6 \%$ of patients have postoperative complications [5]].

Hartmann's is a challenging procedure, but if performed laparoscopically it has various advantages. Our patient, a 60-year-old Italian woman with a history of previous laparoscopic hysterectomy, underwent a laparoscopic Hartmann procedure for bowel perforation secondary to diverticular disease. Six months later she underwent an elective laparoscopic Hartmann reversal. The first step was the reduction of parastomal hernia (Video SI). The second step was mobilization of the splenic flexure. During the previous operation the splenic flexure was not mobilized, so the planes at this level were good. It is not mandatory to isolate the ureter. Usually the rectum is not isolated, but in this case thanks to the use of the handpiece of the circular stapler the wall of the rectum was exposed. The vagina was identified and moved away. The operation was completed with a mechanical circular anastomosis.

\section{Conflicts of interest}

There are no conflicts of interest to declare.

\section{F. Coratti* (iD, C. Maggioni†, C. Mongelli†, T. Nelli† and F. Cianchi† \\ *AOUC Firenze, Firenze, Italy, and †Università degli Studi di Firenze, Florence, Italy \\ E-mail: corattif@gmail.com \\ Received 29 August 2019; accepted 18 September 2019; Accepted Article online 26 September 2019}

\section{References}

1 You H, Sweeny A, Cooper ML, Von Papen M, Innes J. The management of diverticulitis: a review of the guidelines. Med J Aust 2019, https://doi.org/10.5694/ mja2.50276.

2 Golash V. Laparoscopic reversal of Hartmann procedure. J Minim Access Surg 2006; 2: 211-5.

3 Giuseppe R, Nicolò IdF, Serafino M, et al. Laparoscopic reversal of Hartmann's procedure: a single-center experience. Asian J Endosc Surg 2018, https://doi.org/10.1111/ases.12659.

4 Acuna SA, Wood T, Chesney TR, et al. Operative strategies for perforated diverticulitis: a systematic review and metaanalysis. Dis Colon Rectum 2018; 61: 1442-53.

5 Schmidt S, Ismail T, Puhan MA, Soll C, Breitenstein S. Meta-analysis of surgical strategies in perforated left colonic diverticulitis with generalized peritonitis. Langenbecks Arch Surg 2018; 403: 425-33.

\section{Supporting Information}

The video may be found in the online version of this article and also on the Colorectal Disease Journal YouTube and Vimeo channels:

Video S1. Laparoscopic reversal of Hartmann procedure.

\section{Amelioration of intersphincteric resection for low rectal cancer - concentrate on defaecation function - a video vignette}

doi:10.1111/codi.14860

\section{Dear Editor,}

Intersphincteric resection (ISR) [1] was performed in a 55 -year-old woman with a $2 \mathrm{~cm}$ tumour at the dentate line. This patient preserved her defaecation function. Herein, we summarize several steps that benefit defaecation function:

1 Neuroprotection: under laparoscopy, we separated the retro-rectal gap, the Toldt gap around the root of the IMA and finally the tri-junction in the lateral peritoneum. The pelvic nerve plexus could be clearly observed and fully preserved;

2 Simplification of the per anum approach and integrity of the pelvic floor muscles: this occurs at a certain degree of rectal separation. Further dissociation while approaching the end of the mesorectum could lead to entrance into the anal sphincter space;

3 Extent of transanal excision: customizing suitable incisions, such as wedge-shaped resection (Fig. 1), to preserve sensory receptors around the anus.

The operation lasted for $180 \mathrm{~min}$ with blood loss of $20 \mathrm{ml}$. The margins were negative for tumour cells according to intra-operative frozen section pathology. The American Joint Commission on Cancer stage was pT4aN0M0, according to histopathology and computed 